\title{
Nuclear PKR in retinal neurons in the early stage of diabetic retinopathy in streptozotocin-induced diabetic rats
}

\author{
VIVIANE ALINE OLIVEIRA SILVA ${ }^{1^{*}}$, NAYARA DELGADO ANDRÉ ${ }^{2 *}$, THAÍS AMARALE SOUSA ${ }^{3}$, \\ VÂNI MARIA ALVES ${ }^{4}$, ISIS DO CARMO KETTELHUT ${ }^{4}$ and FERNANDO LUIZ DE LUCCA ${ }^{4}$ \\ ${ }^{1}$ Molecular Oncology Research Center, Barretos Cancer Hospital, Barretos, São Paulo 14784-400; \\ ${ }^{2}$ University of São João Del Rei, Divinópolis, Minas Gerais 35501-296; ${ }^{3}$ Federal Institute of Education, \\ Science and Technology of Goiás, Formosa, Goiás 73813-816; ${ }^{4}$ Department of Biochemistry and Immunology, \\ Ribeirão Preto School of Medicine, University of São Paulo, Ribeirão Preto, São Paulo 14049-900, Brazil
}

Received July 13, 2020; Accepted February 16, 2021

DOI: $10.3892 / \mathrm{mmr} .2021 .12253$

\begin{abstract}
Retinal neuron apoptosis is a key component of diabetic retinopathy (DR), one of the most common complications of diabetes. Stress due to persistent hyperglycaemia and corresponding glucotoxicity represents one of the primary pathogenic mechanisms of diabetes and its complications. Apoptosis of retinal neurons serves a critical role in the pathogenesis of DR observed in patients with diabetes and streptozotocin (STZ)-induced diabetic rats. Retinal neuron apoptosis occurs one month after STZ injection, which is considered the early stage of DR. The molecular mechanism involved in the suppression of retinal neuron apoptosis during the early stage of DR remains unclear. RNA-dependent protein kinase (PKR) is a stress-sensitive pro-apoptotic kinase. Our previous study indicated that $\mathrm{PK} R$-associated protein $\mathrm{X}$, a stress-sensitive activator of PKR, is upregulated in the early stage of STZ-induced diabetes. In order to assess the role of PKR in DR prior to apoptosis of retinal neurons, immunofluorescence and western blotting were performed to investigate the cellular localization and expression of PKR in the retina in the early stage of STZ-induced diabetes in rats. PKR activity was indirectly assessed by expression levels of phosphorylated eukaryotic translation initiation factor $2 \alpha$ (p-eIF2- $\alpha$ ) and the presence of apoptotic cells in the retina was investigated by TUNEL assay. The findings revealed that PKR was localized in the nucleus of
\end{abstract}

Correspondence to: Mrs. Viviane Aline Oliveira Silva, Molecular Oncology Research Center, Barretos Cancer Hospital, 1331 Rua Antenor Duarte Villela, Barretos, São Paulo 14784-400, Brazil E-mail: vivianeaos@gmail.com

*Contributed equally

Abbreviations: PKR, RNA-dependent protein kinase; RAX, PKR-associated protein $\mathrm{X}$; mtRNA, mitochondrial RNA; SINE, short interspersed nuclear elements

Key words: diabetic retinopathy, nuclear PKR, retinal neuron, apoptosis retinal ganglion and inner nuclear layer cells from normal and diabetic rats. To the best of our knowledge, the present study is the first to demonstrate nuclear localization of PKR in retinal neurons. Immunofluorescence analysis demonstrated that PKR was expressed in the nuclei of retinal neurons at 3 and 6 days and its expression was decreased at 15 days after STZ treatment. In addition, p-eIF2- $\alpha$ expression and cellular localization followed the trend of PKR, suggesting that this pro-apoptotic kinase was active in the nuclei of retinal neurons. These findings are consistent with the hypothesis that nuclear translocation of PKR may be a mechanism to sequester active PKR, thus preventing upregulation of cytosolic signalling pathways that induce apoptosis in retinal neurons. Apoptotic cells were not detected in the retina in the early stage of DR. A model was proposed to explain the mechanism by which apoptosis of retinal neurons by PKR is suppressed in the early stage of DR. The possible role of mitochondrial RNA (mtRNA) and Alu RNA in this phenomenon is also discussed since it was demonstrated that the cellular stress due to prolonged hyperglycaemia induces the release of mtRNA and transcription of $A l u$ RNA. Moreover, it mtRNA activates PKR, whereas $A l u$ RNA inhibits the activation of this protein kinase.

\section{Introduction}

Diabetic retinopathy (DR) is one of the most common complications of diabetes and the leading cause of vision loss globally $(1,2)$. It is estimated that diabetes will affect $\sim 642$ million people worldwide by 2035 (3) and nearly all patients with type 1 , and more than half with type 2 diabetes, will develop DR (1). DR pathophysiology is complex and involves several mechanisms, such as oxidative stress, mitochondrial dysfunction, an increase in inflammatory mediators and metabolic abnormalities initiated by hyperglycaemia (4-6). Apoptosis of retinal neurons serves a critical role in the pathogenesis of DR observed in patients with diabetes and streptozotocin (STZ)-induced diabetic rats (5,7-9). Retinal neuron apoptosis occurs one month after STZ injection, which is considered the early stage of DR $(6,10)$. The molecular mechanisms involved in the suppression of retinal neuron apoptosis during the early stage of DR remain unclear. 
RNA-dependent protein kinase (PKR) is a serine/threonine-protein kinase implicated in the modulation of the stress response and pro-inflammatory pathways, serving a role in the regulation of critical cell processes (11), including the apoptosis of retinal ganglion cells (RGCs) and neurons in patients with Parkinson's, Alzheimer's and Huntington's disease (12-16). PKR is ubiquitously expressed in mammalian cells and was initially identified by its activation by double-stranded RNA (dsRNA) intermediates during viral infection via a mechanism involving autophosphorylation $(11,17)$. PKR serves an essential role in cell antiviral defence; studies on its activation have been performed primarily with viral and synthetic dsRNA (18-20). Single-stranded RNAs containing secondary structure motifs activate PKR $(14,19)$. Mitochondrial RNA (mtRNA) is present as dsRNA in the cytosol where it interacts with PKR, resulting in PKR autophosphorylation, especially under stress (21).

Notably, the activation of PKR is stress responsive and its induction results in inhibition of cell proliferation, suppression of translation and induction of apoptosis $(15,22,23)$. PKR serves a role in endoplasmic reticulum (ER) stress-dependent apoptosis via the eukaryotic translation initiation factor $2 \alpha$ (eIF2- $\alpha$ )/activating transcription factor 4/CHOP signalling pathway (15) and ER stress has a role in the early stage of DR (24).

PKR-associated protein $\mathrm{X}(\mathrm{RAX})$, a direct activator of PKR, induces apoptosis by activating the PKR signalling pathway under stress (25). Our previous study (26) showed that RAX expression is indirectly modulated by microRNA (miR-29b) at the early stage of STZ-induced diabetic rats. This finding suggests that miR-29b serves a protective effect against apoptosis of retinal neurons via the PKR signalling pathway. The present study investigated the potential mechanisms underlying protection of retinal neurons against apoptosis by PKR in the early stage of DR. The present study investigated the subcellular localization, expression levels and activity of PKR in the retina of normal and STZ-induced diabetic rats.

\section{Materials and methods}

Animals and STZ treatment. A total of 168 Wistar rats (male; weight, 130-150 g; age, 5-6 weeks) were obtained from the Animal Center of School of Medicine, University of São Paulo, São Paulo Brazil. The animals were housed in suspended wire-bottom cages under environmentally controlled temperature $\left(25 \pm 2^{\circ} \mathrm{C}\right)$ and humidity $(55 \pm 5 \%)$ in a $12 / 12 \mathrm{~h}$ dark/light cycle. The animals were provided food and water ad libitum. Animals were maintained under these conditions for $\geq 4$ days prior to the experiments. The animals were randomly divided into seven groups $(\mathrm{n}=8 \mathrm{rats} / \mathrm{group})$ : Control group and six experimental groups, in which animals were killed 3, 6, 15, 22, 28 and 35 days after STZ injection. Experimental diabetes mellitus was induced by single intravenous injection of STZ (Sigma-Aldrich; Merck KGaA) dissolved in $0.01 \mathrm{M}$ citrate buffer $(\mathrm{pH}, 4.5)$ within $5 \mathrm{~min}$ of preparation. The rats were fasted overnight, anesthetized with $5 \%$ isoflurane until loss of righting reflex and were immediately injected with STZ in the jugular vein at a dose of $45 \mathrm{mg} / \mathrm{kg}$ body weight. Control rats received only citrate buffer.

At $24 \mathrm{~h}$ after STZ administration, blood glucose levels were measured via the colorimetric oxidase glucose method
(Labtest) and animals with a blood glucose value $\geq 400 \mathrm{mg} / \mathrm{dl}$ were used in subsequent experiments (27). All experiments were performed between 8:00 and 10:00 a.m. STZ-injected and control rats were sacrificed by rapid cervical dislocation. The death of animals was confirmed by observing cardiac and respiratory arrest for 3-5 min before retinas were dissected and used for analysis of PKR and p-eIF2- $\alpha$ expression levels or immunofluorescence. The care and treatment of the animals received prior institutional approval from the Ethical Commission on Animal Research of the School of Medicine at the University of São Paulo.

TUNEL apoptosis assay. Apoptotic cells in the retina were investigated using a DeadEnd ${ }^{\mathrm{TM}}$ Colorimetric TUNEL system (Promega Corporation) according to the manufacturer's protocol. Briefly, slides were fixed in $4 \%$ formaldehyde for $15 \mathrm{~min}$ at room temperature and then washed with PBS before permeabilization with protein $\mathrm{k}(10 \mathrm{ng} / \mathrm{ml}$ for $15 \mathrm{~min})$. The slides were rewashed in PBS, fixed in $4 \%$ paraformaldehyde for $15 \mathrm{~min}$ at room temperature and immersed in PBS. Both test and negative control slides were covered with buffer solution (Promega Corporation) while the positive control reaction was performed. For the positive control, DNase I and its respective buffer (Promega Corporation) were added for $10 \mathrm{~min}$ at $37^{\circ} \mathrm{C}$ in a humid chamber. The negative control was performed using RNase-free water instead of DNase. The slides were then washed in $2 \mathrm{X}$ saline-sodium citrate buffer diluted in deionized water (1:10), incubated for $5 \mathrm{~min}$ at room temperature in $0.3 \%$ hydrogen peroxide, diluted in PBS and washed twice with PBS (5 min each). Horseradish peroxidase (HRP)-labelled streptavidin solution was prepared at a 1:500 dilution in PBS. Each slide received $100 \mu 1$ streptavidin-HRP and was incubated for $5 \mathrm{~min}$ at room temperature followed by washing in PBS. Finally, the slides were incubated in $1 \mathrm{X}$ DAB solution (DAB 10X chromogen in DAB substrate $1 \mathrm{X}$ Buffer) for $10 \mathrm{~min}$ in a humid dark chamber at room temperature. The slides were dehydrated, mounted in Permount (Thermo Fisher Scientific, Inc.) and examined under a light microscope (Leica DFC 340 FX; Leica Microsystems $\mathrm{GmbH})$ at an original magnification of x100.

Immunofluorescence. Enucleated eyes were fixed using $4 \%$ buffered paraformaldehyde dissolved in $0.2 \mathrm{M}$ phosphate buffer ( $\mathrm{pH} 7.3$ ) for $24 \mathrm{~h}$ at $4^{\circ} \mathrm{C}$, then treated with $70 \%$ ethanol $(2 \mathrm{~h}), 99 \%$ ethanol $(1 \mathrm{~h})$, absolute ethanol (30 min) and xylene $(1 \mathrm{~h})$ at room temperature, followed by treatment with xylene for $10 \mathrm{~min}$ at $37^{\circ} \mathrm{C}$ before being placed in a paraffin bath $\left(1 \mathrm{~h} ; 56^{\circ} \mathrm{C}\right)$. The fixed samples were subjected to vacuum pressure for $30 \mathrm{~min}$ and then embedded in paraffin ( 2 baths at $60^{\circ} \mathrm{C}, 2 \mathrm{~h}$ each). The paraffin blocks were cut into $5-\mu \mathrm{m}$ serial sections and placed on Superfrost $^{\mathrm{TM}}$ (Cole-Parmer Ltd.; Thermo Fisher Scientific, Inc.) slides. In order to confirm cellular integrity, the samples were stained using Harris hematoxylin and eosin-phloxine. Sections were adhered to the slides in an oven at $80^{\circ} \mathrm{C}$ for $15 \mathrm{~min}$, deparaffinized in xylene and rehydrated via graded ethanol washes $(100,95,80$, and $70 \%)$ for $10 \mathrm{~min}$ each, followed by washing in distilled water for $5 \mathrm{~min}$. Sections were stained at room temperature with $5 \% \mathrm{w} / \mathrm{v}$ hematoxylin in water for $1 \mathrm{~min}$, washed in distilled water and stained with $0.5 \% \mathrm{w} / \mathrm{v}$ eosin in water for $2 \mathrm{~min}$. Samples were blocked at room temperature in $1 \%$ goat serum, $2 \%$ BSA and $0.05 \%$ Triton X-100 in PBS for 


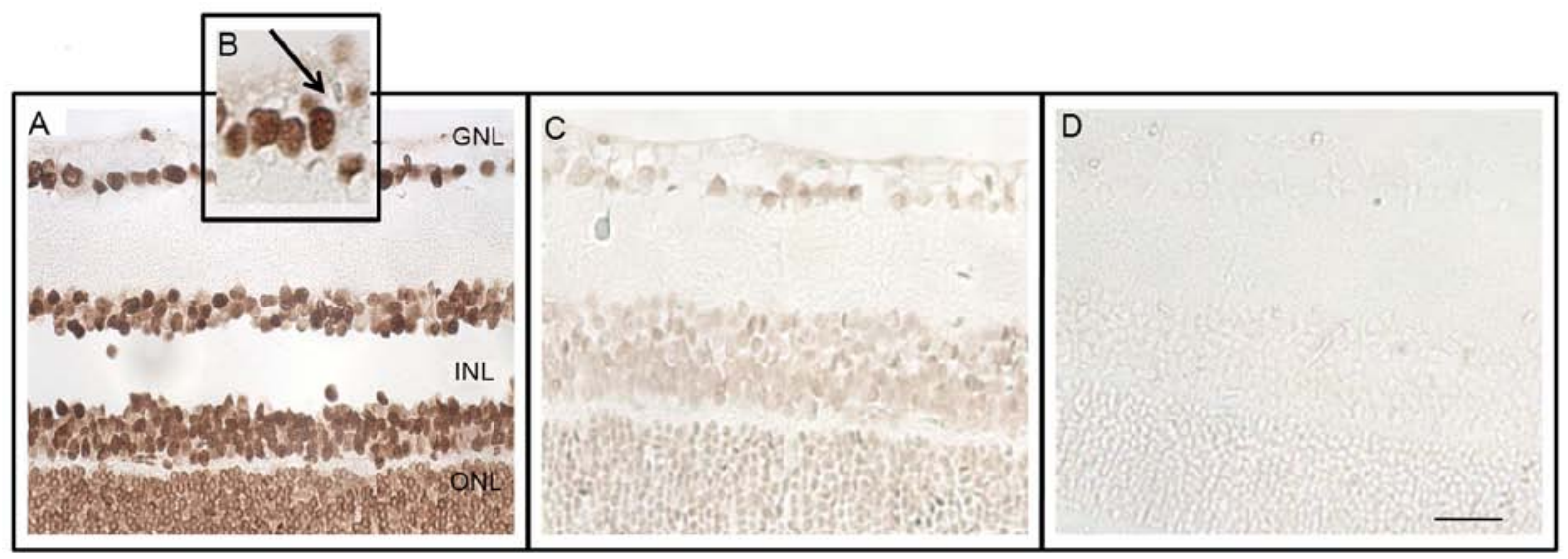

Figure 1. TUNEL staining of retinal tissues in normal and diabetic rats. Representative photomicrographs of retinal sections were evaluated for apoptosis by TUNEL assay at day 35. (A) Photomicrograph of the retina of a diabetic animal from day 35 treated with DNase I (positive control). (B) Magnification of the GCL of the positive control shows condensed and fragmented nuclei and TUNEL-positive cells. (C) Photomicrograph of the retina of a diabetic animal 35 days after treatment with streptozotocin. (D) Negative control (absence of terminal deoxynucleotidyl transferase recombinant enzyme). Magnification, 100x. Scale bar, $50 \mu \mathrm{m}$. GCL, ganglion cell layer; INL, inner nuclear layer; ONL, outer nuclear layer.

$1 \mathrm{~h}$, then incubated with anti-PKR mouse monoclonal (1:50; cat.no. sc-6282; Santa Cruz Biotechnology,Inc.) or anti-p-eIF2- $\alpha$ rabbit polyclonal antibodies (1:50; cat. no. 44-728G; Thermo Fi sher Scientific, Inc.) for $3 \mathrm{~h}$ at $4^{\circ} \mathrm{C}$. The samples were washed for $15 \mathrm{~min}$ in PBS and incubated with species-specific fluorescent Alexa Fluor 594 rabbit anti-mouse or goat anti-rabbit $(\mathrm{H}+\mathrm{L})$ (both 1:2,000; cat. nos. A-11062 and A-11037, respectively; both Thermo Fisher Scientific, Inc.) in a humidified chamber at room temperature for $1 \mathrm{~h}$ in the dark. Then, slides were mounted in Vectashield Mounting Medium with DAPI (Sigma-Aldrich; Merck KGaA) and examined under a microscope (magnification, x100; Leica DFC 340 FX). Images were analyzed using Adobe PhotoShop CS6 version 13.0x 64 software (Adobe Systems, Inc.). The specificity of antibody staining was confirmed by incubating adjacent sections in the absence of the primary antibody.

Western blot analysis. Total protein was extracted from rat retina using lysis buffer [20 mM Tris- $\mathrm{HCl}(\mathrm{pH} 7.6), 400 \mathrm{mM}$ $\mathrm{NaCl}, 50 \mathrm{mM} \mathrm{KCl}, 0.2 \mathrm{mM}$ phenylmethylsulfonyl fluoride, $2 \mu \mathrm{g} / \mathrm{ml}$ leupeptin, $2 \mu \mathrm{g} / \mathrm{ml}$ aprotinin, $1 \mathrm{mM}$ dithiothreitol, 1 mM EDTA, $1 \%$ Triton X-100 and 20\% glycerol]. All reagents were purchased from Sigma-Aldrich (Merck KGaA). The homogenates were centrifuged at $15,500 \times \mathrm{g}$ at $4^{\circ} \mathrm{C}$ for $40 \mathrm{~min}$ and the supernatant was used for analysis. The protein concentrations were determined using Pierce BCA Protein Assay (Thermo Fisher Scientific, Inc.). Equal amounts of protein $(30 \mu \mathrm{g})$ were separated by electrophoresis using a $10 \%$ SDS-PAGE resolving gel with 4\% SDS-PAGE stacking gel and transferred onto a Hybond-C-supported nitrocellulose membrane (Amersham Biosciences; Cytiva). The membranes were subsequently blocked with $3 \% \mathrm{BSA}$ in $100 \mathrm{mM}$ Tris- $\mathrm{HCl}$ (pH 7.5), $100 \mathrm{mM} \mathrm{NaCl}, 0.1 \%$ Tween-20 (TBST) for $1 \mathrm{~h}$ at $4^{\circ} \mathrm{C}$ with gentle agitation. After washing in TBST for $20 \mathrm{~min}$, the membranes were incubated overnight with anti-PKR (1:300; cat. no. sc-6282; Santa Cruz Biotechnology, Inc.) and anti- $\beta$-actin mouse monoclonal antibodies at $4^{\circ} \mathrm{C}(1: 1,000$; cat. no. sc-517582; Santa Cruz Biotechnology, Inc.). The membranes were subsequently washed with TBST for $20 \mathrm{~min}$ and incubated with
HRP-conjugated anti-mouse IgG $\kappa$ binding protein $(1: 5,000$; cat. no. sc-516102; Santa Cruz Biotechnology, Inc.) antibodies diluted in TBST at room temperature for $60 \mathrm{~min}$. Membranes were washed for $20 \mathrm{~min}$ with TBST. Antibody-labeled protein bands were visualized with enhanced chemiluminescence detection reagents (Amersham Biosciences; Cytiva) according to the manufacturer's protocol. The films were observed and the intensity of protein bands was determined using ImageJ v1.4.1 software (National Institutes of Health).

Statistical analysis. Data are presented as the mean $\pm \mathrm{SD}(\mathrm{n}=3)$ and were analyzed by one-way ANOVA followed by Dunnett's post hoc test. Statistical analysis was performed using GraphPad Prism software (version 4.0; GraphPad Software, Inc.). $\mathrm{P}<0.05$ was considered to indicate a statistically significant difference.

\section{Results}

TUNEL apoptosis assays. The in situ presence of apoptotic cells in the sections of control and treated rat retina following STZ injection on days $6,15,22$, and 35 was investigated by the TUNEL method. The morphological patterns obtained in the positive control, such as condensed and fragmented nuclei and the presence of apoptotic bodies, were compared with retinal cells of the diabetic and negative groups (Fig. 1A and B). At 35 days after treatment with STZ (Fig. 1C), there was no increase in the number of apoptotic cells, indicating that the present study evaluated molecular events that preceded apoptosis of neurons in the retina of diabetic rats. The negative control is shown in Fig. 1D.

Expression levels of PKR protein. Western blot analysis showed that PKR protein expression levels did not change on days 3 and 6 after STZ treatment compared with the control (Fig. 2). However, on days 15, 22, 28 and 35, a significant decrease in PKR protein expression levels was observed.

Cellular localization of PKR. Cellular localization of PKR was investigated in the retina of normal and diabetic rats on days 3, 6 

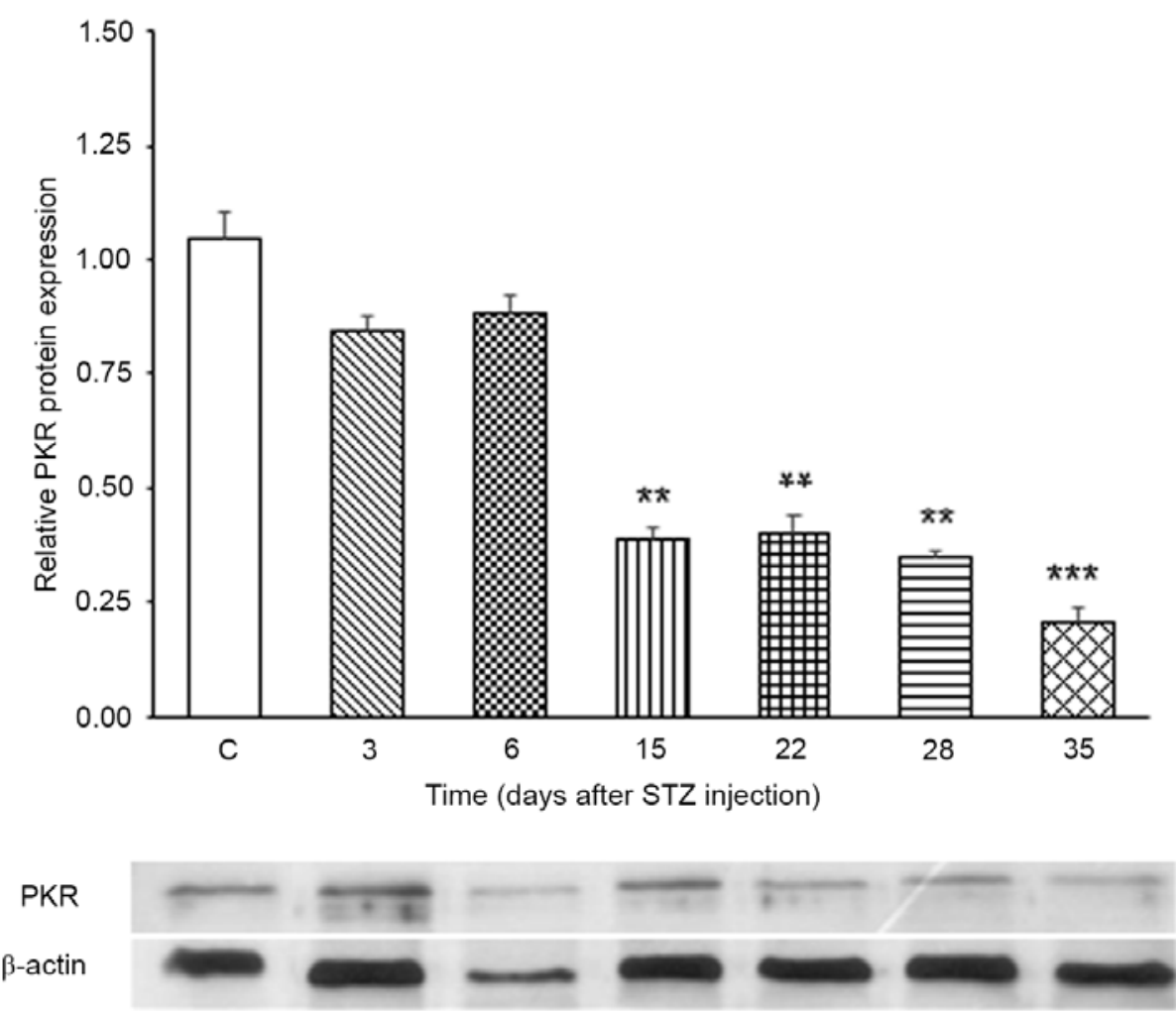

Figure 2. PKR protein expression levels in the retina of normal and diabetic rats. PKR protein expression levels were evaluated by western blot analysis of retinas of normal and diabetic rats. Data are presented as the mean \pm SEM $(n=3) .{ }^{* *} \mathrm{P}<0.01,{ }^{* * *} \mathrm{P}<0.001$ vs. C. PKR, RNA-dependent protein kinase; $\mathrm{C}$, control; STZ, streptozotocin.

and 35 after STZ injection (Fig. 3). PKR staining was observed in the nuclei of RGCs and INL cells. No change was observed in the cellular localization of PKR in the retinas of normal or diabetic rats. However, expression levels of nuclear PKR in the retinas of diabetic rats were more evident on days 3 and 6 (Fig. 3B and C) compared with control animals (Fig. 3A). Minimal expression was detected at 35 days after STZ injection (Fig. 3D). The DAPI-stained nuclei are shown in Fig. 3E-H and the negative controls in Fig. 3I-L. PKR protein nuclear staining on day 6 after STZ injection is presented in Fig. 4.

Cellular localization of $p$-eIF2- $\alpha$. Activated eIF2- $\alpha$ protein (p-eIF2- $\alpha$ ) was expressed in the same retinal neurons where PKR was detected from the retina observed for PKR (Fig. 5). In addition, the number of p-eIF2- $\alpha$-positive retinal cells was the same in the normal and diabetic groups (Fig. 5A-C). Nuclear expression of p-eIF2- $\alpha$ in RGCs and the inner nuclear layer (INL) was observed at 3 and 6 days. Moreover, at 35 days after STZ injection, p-eIF2- $\alpha$ expression levels were decreased in the retina of treated rats compared with controls (Fig. 5A and D). The DAPI-stained nuclei are shown in Fig. 5E-H and the negative controls in Fig. 5I-L.

\section{Discussion}

The present study evaluated the subcellular localization, expression levels and activity of the pro-apoptotic kinase PKR in retinal neurons during the first 35 days after STZ injection, which is considered the early stage of DR in this experimental model of type 1 diabetes (28). The first step was to investigate
PKR expression levels and subcellular localization in the retina of control and STZ-treated rats. PKR protein expression levels were downregulated at 15, 22, and 28 days and PKR was localized in the nuclei of RGCs and INL cells in the rat retina. To the best of our knowledge, this is the first demonstration of the nuclear localization of PKR in retinal neurons. The activation of PKR was indirectly assessed by eIF2- $\alpha$ phosphorylation, as previously reported (29). A strong signal of p-eIF2- $\alpha$-positive cells was observed up to 22 days after STZ treatment compared with normal retinas. In addition, analysis of cellular localization of p-eIF2- $\alpha$ showed that this protein was strongly expressed in the nucleus of neurons of the GCL in the retina of diabetic animals, suggesting that nuclear PKR was active in retinal neurons of diabetic rats.

PKR is stress-sensitive and considered to be one of the most important pro-apoptotic kinases $(15,22,23)$. Thus, cellular stress due to glucotoxicity in the early stage of DR induced by STZ may activate PKR and consequently induce apoptosis of retinal neurons. However, the present study did not detect apoptosis in retinal neurons in spite of the presence of active PKR in these cells.

The accumulation of active PKR in the nucleus has been proposed as a cellular stress response $(30,31)$. It has been linked to several types of pathology, such as leukaemia development (30), radiation resistance in lung cancer (32), sporadic Alzheimer's disease (33), Creutzfeldt-Jakob disease (34) and myelodysplastic syndrome (31). The accumulation of active PKR has also been reported in the nuclei of cells treated with tunicamycin, an ER stress inductor, and in brain neurons of patients with Parkinson's and Huntington's disease (12,35). The 


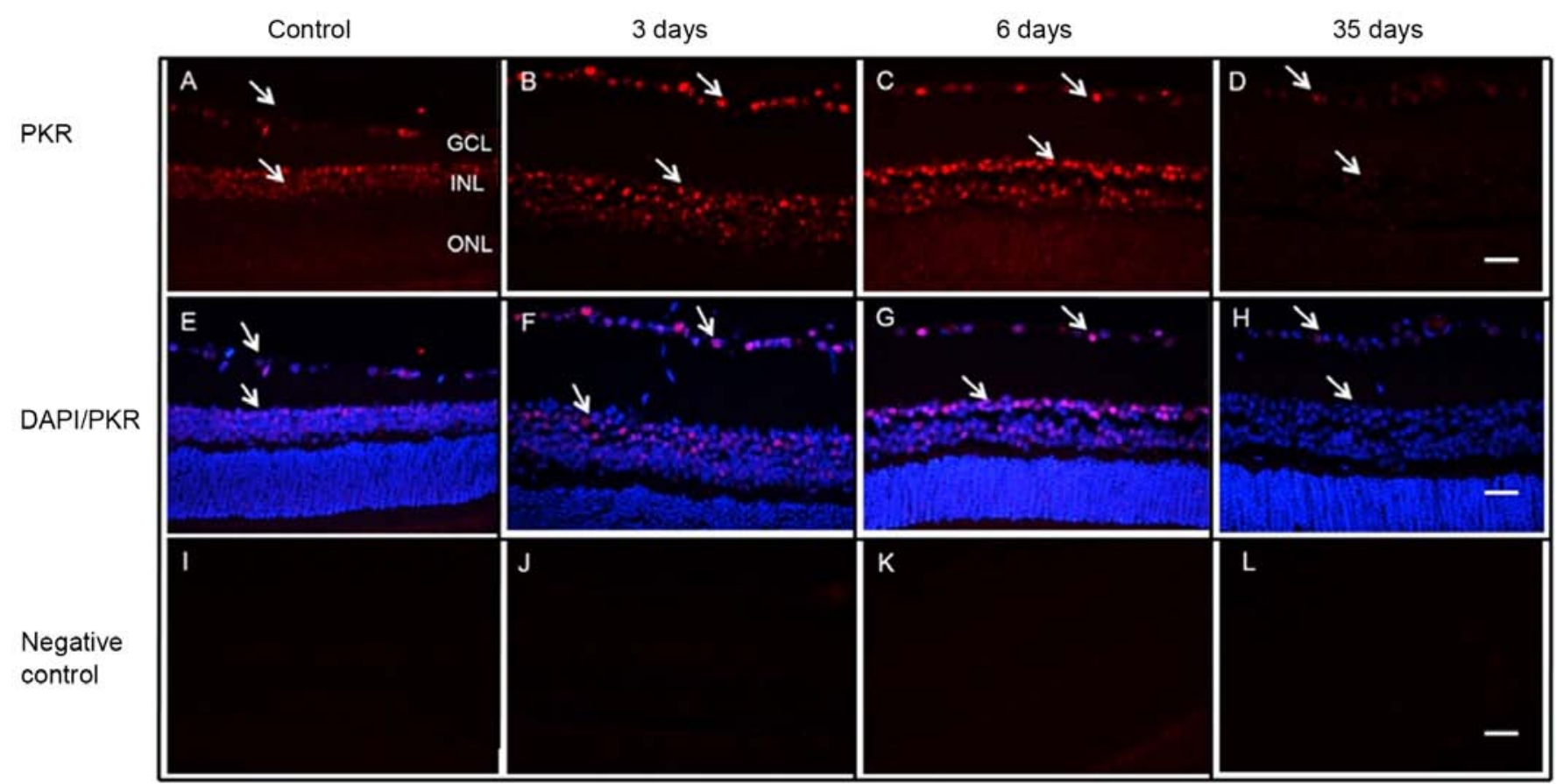

Figure 3. Immunofluorescence analysis of PKR cellular localization in the retina of normal and diabetic rats. Sections of (A) normal and diabetic rat retinas at (B) 3, (C) 6 and (D) 35 days. DAPI-stained nuclei in (E) normal and diabetic rat retinas at (F) 3, (G) 6 and (H) 35 days. Negative control of (I) normal and diabetic rat retinas at (J) 3, (K) 6 and (L) 35 days. PKR protein expression is indicated by arrows. Magnification, 100x. Scale bar, $50 \mu \mathrm{m}$. PKR, RNA-dependent protein kinase; GCL, ganglion cell layer; INL, inner nuclear layer; ONL, outer nuclear layer.
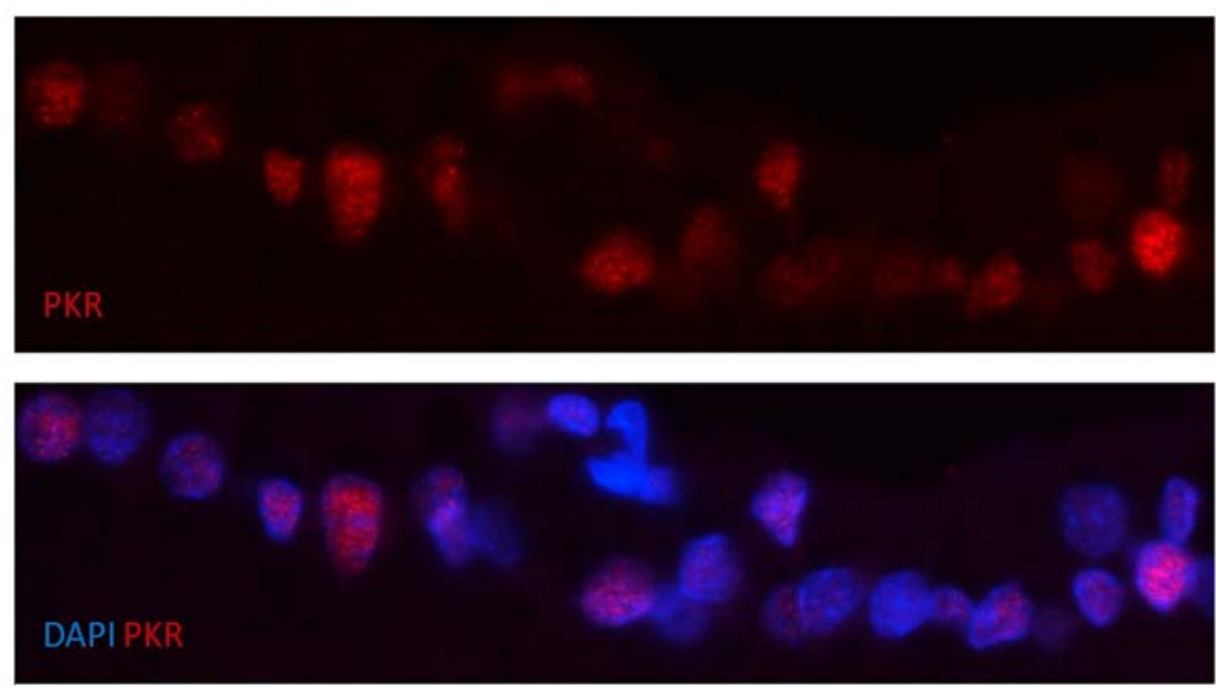

Figure 4. Immunofluorescence analysis of nuclear localization of PKR in the ganglion cell layer of the retina of diabetic rats. PKR protein nuclear staining contrasted with nuclear marker DAPI in retinal ganglion cells on day 6 after streptozotocin injection. Magnification, x400. PKR, RNA-dependent protein kinase.

biological significance of PKR translocation to the nucleus is not entirely understood. Blalock et al (30) reported that PKR is phosphorylated in patients with myelodysplastic syndrome and its subcellular localization depends on disease severity. Their findings suggested that nuclear translocation of PKR may be a mechanism to sequester active PKR, thus preventing this stress kinase from activating signalling pathways in the cytosol.

Previous work has revealed that cellular stress due to hyperglycaemia is responsible for mitochondrial dysfunction (36). It was also demonstrated that mtRNA is released into the cytosol and forms intermolecular dsRNAs that activate cytoplasmic PKR $(21,37)$. Moreover, it has been shown that different types of cellular stress, including that induced by hyperglycaemia, can induce transcription of $A l u$ elements that belong to the short interspersed nuclear elements (SINE) family and are present at more than one million copies in the human genome $(38,39)$. Alu RNA inhibits cytoplasmic PKR, suggesting a functional role for mammalian SINEs, which have previously been considered junk DNA (40). Accumulating evidence supports the 


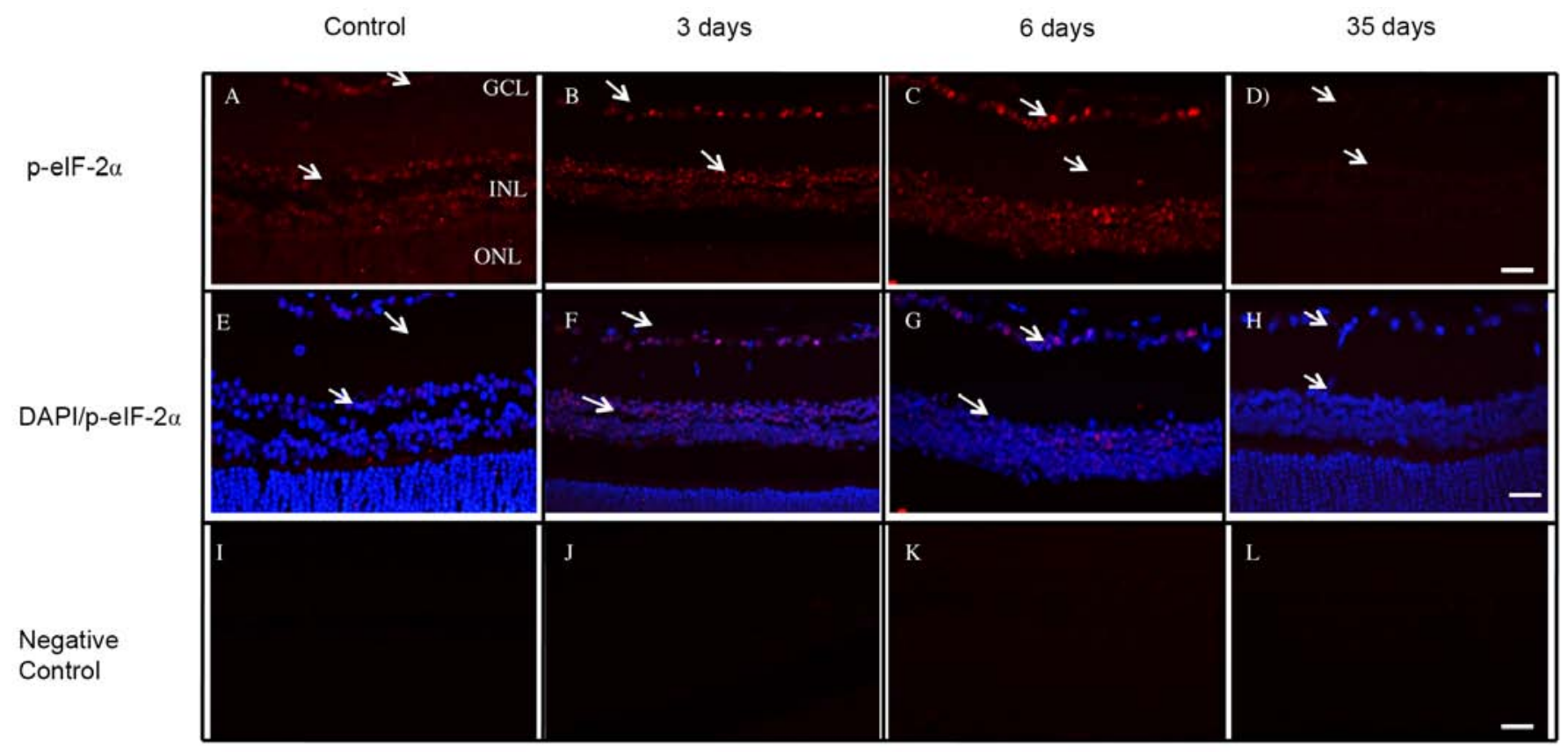

Figure 5. Immunofluorescence analysis of p-eIF2- $\alpha$ cellular localization in the retina of normal and diabetic rats. Sections of (A) normal and diabetic rat retinas at (B) 3, (C) 6 and (D) 35 days. DAPI-stained nuclei in the retina of (E) normal and diabetic rats at (F) 3, (G) 6 and (H) 35 days. Negative controls of (I) normal and diabetic rat retinas at (J) 3, (K) 6 and (L) 35 days. Arrows indicate p-eIF2- $\alpha$ protein. Magnification, x100. Scale bar, $50 \mu \mathrm{m}$. p-eIF2- $\alpha$, phosphorylated eukaryotic translation initiation factor $2 \alpha$; GCL, ganglion cell layer; INL, inner nuclear layer; ONL, outer nuclear layer.

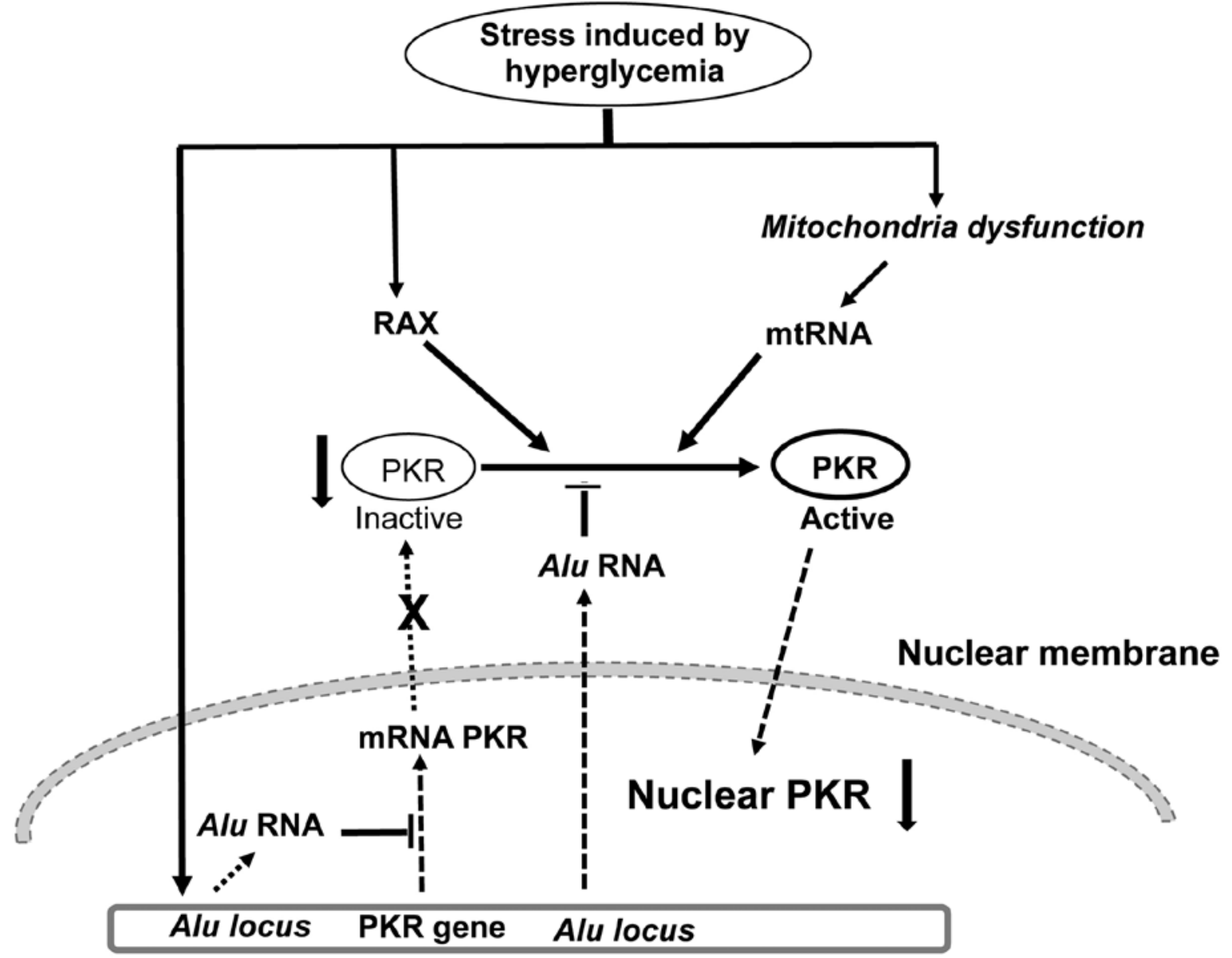

DNA

Figure 6. Overview of the proposed mechanism underlying downregulation of nuclear PKR expression in retinal neurons in the early stage of diabetic retinopathy in streptozotocin-treated animals. PKR, RNA-dependent protein kinase; RAX, PKR associated protein X; mtRNA, mitochondrial RNA; Alu, a class of retroelements termed short interspersed nuclear elements. 
concept that $A l u$ RNAs serve a functional role during the stress response. Alu RNA inhibits the transcription of genes involved in the response to heat shock (39) and can inhibit activation of the cytoplasmic PKR (40). The induction of Alu element transcription in hyperglycaemic endothelial cells has been observed, which is responsible for inhibition of the synthesis of nitric oxide synthase and superoxide dismutase 2 (41).

Based on the present results and the literature, we proposed a mechanism to explain the decrease in nuclear PKR expression levels in retinal neurons at 35 days after STZ treatment (Fig. 6). We hypothesize that stress caused by hyperglycaemia induces RAX expression (26) and mitochondrial dysfunction, with subsequent release of mtRNA into the cytosol of neurons $(21,37)$. RAX and mtRNA activate PKR in the cytosol of retinal neurons, which is followed by its nuclear translocation. Nuclear translocation of active PKR has previously been suggested as a cell protection mechanism against the pro-apoptotic activity of PKR (31). Stress caused by hyperglycaemia induces the expression of Alu RNAs (41), which inhibit transcription of the PKR gene and activation of PKR (39), leading to a decrease in nuclear PKR protein expression levels in retinal neurons of STZ-induced diabetic animals. Thus, the present results suggest a novel mechanism that may underly the protection of retinal neurons from apoptosis by PKR at the early stage of DR, in addition to the inhibition of RAX expression by miR-29b, as previously described (26). Bone marrow mononuclear cells of high-risk patients with myelodysplastic syndrome display nuclear localization of active PKR and a lower number of apoptotic cells compared with low-risk patients (31). In conclusion, the present study may contribute to understanding of the biological significance of PKR nuclear translocation observed in pathologies, such as myelodysplastic syndrome (31) and Alzheimer's (33) and Creutzfeldt-Jakob disease (34).

\section{Acknowledgements}

The authors would like to thank Cacilda Pereira and Zuleica Moraes from the Department of Biochemistry and Immunology and Neusa Maria Zanon from the Department of Physiology, Ribeirão Preto School of Medicine, São Paulo, Brazil, for technical assistance.

\section{Funding}

The present study was supported by Research Support Foundation of the State of São Paulo (grant no. 08/58325-4) and Coordination for higher Education Staff Development.

\section{Availability of data and materials}

The datasets used and/or analyzed during the present study are available from the corresponding author on reasonable request.

\section{Authors' contributions}

VAOS and FLDL designed the experiments and wrote the manuscript. VAOS, NDA, TAES, IDCK and VMA performed the experiments. VAOS and NDA analyzed the data. All authors discussed the data and commented on the manuscript.
VAOS, NDA and FLDL confirm the authenticity of all the raw data. All authors read and approved the final version of the manuscript.

\section{Ethics approval and consent to participate}

The present study was approved by the Ethical Commission on Animal Research of the School of Medicine at the University of São Paulo (approval no. 012/2008).

\section{Patient consent for publication}

Not applicable.

\section{Competing interests}

The authors confirm that they have no competing interests.

\section{References}

1. Fong DS, Aiello L, Gardner TW, King GL, Blankenship G, Cavallerano JD, Ferris FL III and Klein R; American Diabetes Association: Diabetic retinopathy. Diabetes Care 26: 226-229, 2003.

2. Antonetti DA, Klein R and Gardner TW: Diabetic retinopathy. N Engl J Med 366: 1227-1239, 2012.

3. Guariguata L, Whiting DR, Hambleton I, Beagley J, Linnenkamp U and Shaw JE: Global estimates of diabetes prevalence for 2013 and projections for 2035. Diabetes Res Clin Pract 103:137-149, 2014.

4. Kowluru RA and Mishra M: Oxidative stress, mitochondrial damage and diabetic retinopathy. Biochim Biophys Acta 1852: 2474-2483, 2015

5. Barber AJ: Diabetic retinopathy: Recent advances towards understanding neurodegeneration and vision loss. Sci China Life Sci 58: 541-549, 2015.

6. Ung L, Pattamatta U, Carnt N, Wilkinson-Berka JL, Liew G and White AJR: Oxidative stress and reactive oxygen species: A review of their role in ocular disease. Clin Sci 131: 2865-2883, 2017.

7. Barber AJ, Lieth E, Khin SA, Antonetti DA, Buchanan AG and Gardner TW: Neural apoptosis in the retina during experimental and human diabetes: Early onset and effect of insulin. J Clin Invest 102: 783-791, 1998

8. Oshitari T and Roy S: Diabetes: A potential enhancer of retinal injury in rat retinas. Neurosc Lett 390: 25-30, 2005.

9. Luo D, Fan Y and Xu X: The effects of aminoguanidine on retinopathy in STZ-induced diabetic rats. Bioorg Med Chem Lett 22: 4386-4390, 2012.

10. Naderi A, Zahed R, Aghajanpour L, Amoli FA and Lashay A: Long term features of diabetic retinopathy in streptozotocin-induced diabetic Wistar rats. Exp Eye Res 184: 213-220, 2019.

11. Gal-Ben-Ari S, Barrera I, Ehrlich M and Rosenblum K: PKR: A Kinase to Remember. Front Mol Neurosci 11: 480, 2019.

12. Bando Y, Onuki R, Katayama T, Manabe T, Kudo T, Taira K and Tohyama M: Double-strand RNA dependent protein kinase (PKR) is involved in the extrastriatal degeneration in Parkinson's disease and Huntington's disease. Neurochem Int 46: 11-18, 2005.

13. Page G, Rioux Bilan A, Ingrand S, Lafay-Chebassier C, Pain S, Perault Pochat MC, Bouras C, Bayer T and Hugon J: Activated double-stranded RNA-dependent protein kinase and neuronal death in models of Alzheimer's disease. Neuroscience 139: 1343-1354, 2006.

14. García MA, Gil J, Ventoso I, Guerra S, Domingo E, Rivas C and Esteban M: Impact of protein kinase PKR in cell biology: From antiviral to antiproliferative action. Microbiol Mol Biol Rev 70: 1032-1060, 2006

15. Lee ES, Yoon C, Kim Y and Bae Y: The double-strand RNA-dependent protein kinase PKR plays a significant role in a sustained ER stress-induced apoptosis. FEBS Lett 581: 4325-4332, 2007.

16. Hugon J, Mouton-Liger F, Dumurgier $J$ and Paquet C: PKR involvement in Alzheimer's disease. Alzheimer Res Ther 9: 83, 2017. 
17. Ung TL, Cao C, Lu J, Ozato K and Dever TE: Heterologous dimerization domains functionally substitute for the double-stranded RNA binding domains of the kinase PKR. EMBO J 20 : 3728-3737, 2001.

18. Williams BR: Signal integration via PKR. Sci STKE 2001: re2, 2001.

19. De Lucca FL, Serrano SV, Souza LR and Watanabe MA: Activation of RNA-dependent protein kinase and nuclear factor-kB by regulatory RNA from lipopolysaccharide-stimulated macrophages: Implications for cytokine production. Eur J Pharmacol 450: 85-89, 2002.

20. Robertson HD and Mathews MB: The regulation of the protein kinase PKR by RNA. Biochimie 78: 909-914, 1996.

21. Kim Y, Lee JH, Park JE, Cho J, Yi H and Kim VN: PKR is activated by cellular dsRNAs during mitosis and acts as a mitotic regulator. Genes Dev 28: 1310-1322, 2014.

22. Lee SB and Esteban M: The interferon-induced double-stranded RNA-activated protein kinase induces apoptosis. Virology 199 491-496, 1994

23. Gil J and Esteban M: Induction of apoptosis by the dsRNA-dependent protein kinase (PKR): Mechanism of action. Apoptosis 5: 107-114, 2000

24. Li B, Wang HS, Li GG, Zhao MJ and Zhao MH: The role of endoplasmic reticulum stress in the early stage of diabetic retinopathy. Acta Diabetol 48: 103-111, 2011.

25. Ito T, Yang M and May WS: RAX, a cellular activator for double-stranded RNA-dependent protein kinase during stress signaling. J Biol Chem 274: 15427-15432, 1999.

26. Silva VA, Polesskaya A, Sousa TA, Corrêa VM, André ND, Reis RI, Kettelhut IC, Harel-Bellan A and De Lucca FL: Expression and cellular localization of microRNA-29b and RAX, an activator of the RNA-dependent protein kinase (PKR), in the retina of streptozotocin-induced diabetic rats. Mol Vis 17: 2228-2240, 2011.

27. Trinder P: Determination of blood glucose using 4-amino phenazone as oxygen acceptor. J Clin Pathol 22: 246, 1969.

28. Furman BL: Streptozotocin-induced diabetic models in mice and rats. Curr Protoc Pharmacol 70: 5.47.1-5.47.20, 2015.

29. Muaddi H, Majumder M, Peidis P, Papadakis AI, Holcik M, Scheuner D, Kaufman RJ, Hatzoglou M and Koromilas AE: Phosphorylation of eIF2 $\alpha$ at serine 51 is an important determinant of cell survival and adaptation to glucose deficiency. Mol Biol Cell 21: 3220-3231, 2010.

30. Blalock WL, Bavelloni A, Piazzi M, Tagliavini F, Faenza I, Martelli AM, Follo MY and Cocco L: Multiple forms of PKR present in the nuclei of acute leukemia cells represent an active kinase that is responsive to stress. Leukemia 25: 236-245, 2011.
31. Follo MY, Finelli C, Mongiorgi S, Clissa C, Bosi C, Martinelli G, Blalock WL, Cocco L and Martelli AM: PKR is activated in MDS patients and its subcellular localization depends on disease severity. Leukemia 22: 2267-2269, 2008.

32. Hao C, Shao R, Raju U, Fang B, Swisher SG and Pataer A: Accumulation of RNA-dependent protein kinase (PKR) in the nuclei of lung cancer cells mediates radiation resistance. Oncotarget 7: 38235-38242, 2016.

33. Bose A, Mouton-Liger F, Paquet C, Mazot P, Vigny M, Gray F and Hugon J: Modulation of tau phosphorylation by the kinase PKR: Implications in Alzheimer's disease. Brain Pathol 21: 189-200, 2010.

34. Paquet C, Bose A, Polivka M, Peoch K, Brouland JP, Keohane C, Hugon $\mathrm{J}$ and Gray F: Neuronal phosphorylated RNA-dependent protein kinase in Creutzfeldt-Jakob disease. J Neuropathol Exp Neurol 68: 190-198, 2009.

35. Onuki R, Bando Y, Suyama E, Katayama T, Kawasaki H, Baba T, Tohyama M and Taira K: A RNA-dependent protein kinase is involved in tunicamycin-induced apoptosis and Alzheimer's disease. EMBO J 23: 959-968, 2004.

36. Dey A and Swaminathan K: Hyperglycemia-induced mitochondrial alterations in liver. Life Sci 87: 197-214, 2010.

37. Kim Y, Park J, Kim S, Kim M, Kang MG, Kwak C, Kang M, Kim B, Rhee HW and Kim VN: PKR senses nuclear and mitochondrial signals by interacting with endogenous double-stranded RNAs. Mol Cell 71: 1051-1063.e6, 2018.

38. Chen LL and Yang L: ALUternative regulation for gene expression. Trends Cell Biol 27: 480-490, 2017.

39. Liu WM, Chu WM, Choudary PV and Schmid CW: Cell stress and translational inhibitors transiently increase the abundance of mammalian SINE transcripts. Nucleic Acids Res 23: 1758-1765, 1995.

40. Chu WM, Ballard R, Carpick BW, Williams BR and Schmid CW: Potential alu function: Regulation of the activity of double-stranded rna-activated kinase PKR. Mol Cell Biol 18: 58-68, 1998.

41. Wang W, Wang W, Azadzoi KM, Dai P, Wang Q, Sun JB, Zhang WT, Shu Y, Yang JH and Yan Z: Alu RNA accumulation in hyperglycemia augments oxidative stress and impairs eNOS and SOD2 expression in endothelial cells. Mol Cell Endocrinol 426: 91-100, 2016

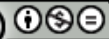

This work is licensed under a Creative Commons Attribution-NonCommercial-NoDerivatives 4.0 International (CC BY-NC-ND 4.0) License. 